\title{
International Association for Testing Materials
}

\section{LONDON CONGRESS}

$\mathrm{I}^{\mathrm{N}}$ opening the Congress of the International Association for Testing Materials at the Institution of Civil Engineers on April 19 and in welcoming the visitors from abroad, Sir William Bragg suggested that the name did not quite fully convey the extent of the Association's work and interests, which include the investigation of the nature and properties of materials and make use of the whole range of available methods, from the most highly scientific to those which are entirely empirical. This is well illustrated in the range of papers which have been presented by prominent workers in this exploratory field and engaged in most, if not all, of the twenty-five countries which were represented at this meeting. The function of the Association is to secure international co-operation and an exchange of views, experience and knowledge in regard to materials and their testing. As has been pointed out by Dr. H. J. Gough, chairman of the British Committee responsible for the arrange. ments, the achievements of this age of great scientific and technical development owe much to the presentday knowledge and skilful use of the properties of materials. Direct application of these are of prime importance in transport, power generation and supply, construction, inter-communication and even in some forms of entertainment. Further, the study of existing materials leads to the production of new and improved materials, and it is this study which the Association promotes and, by means of such as the present Congress, the results and ideas are discussed. Once entirely empirical, the study of materials is now developing along lines of scientific method and, in due course, may become established as a true science.

In connexion with this meeting, an exhibition of testing plant and apparatus was arranged; manufacturers of the instruments and machines used in this class of work have collaborated with the organizers in showing their most up-to-date and reliable products. Although described as limited in size and scope, the range and comprehensiveness are remarkable, so that only a few of the most recent apparatus can be referred to in detail.

Refractory laboratory ware in alumina, now manufactured in England, is suitable for temperatures up to $1,950^{\circ} \mathrm{C}$. for the fusion of metals, alloys and alkalis, and is highly resistant to the action of fuzed metals, oxides, salts and acids, while its high electrical resistance makes it eminently suitable as an insulator at high temperatures. The possibilities of the practical applications of the fluorescence test in food testing, police work, banking, philately-to take just a few random cases - are indicated by the useful types of lamps made by several firms. The Smith wear and lubricant tester is a new type of machine using a steel ball as the active member and its worn impression on the sample as the means of measurement. The cement-testing pistol makes a ball impression by a blow on the surface of the standing cement, and is claimed to give a measure of the compressive strength. For the rapid and accurate estimation of the specific gravity of gases, the new type of balance devised by Messrs. Hales and Moss, of the Fuel Research Station, is of particular interest. It operates by measuring the loss of buoyancy of an air bulb in an atmosphere of the gas in question. The Griffin Gale testing machine enables tensile, compression, indentation and bending tests to be carried out on small samples of metals and other solid materials. In the same class is the Hounsfield tensometer, while the Quinney autographic testing machine is of larger scale and gives load extension diagrams recorded by a pointer moving on smoked glass. Several firms engaged in research exhibited apparatus devised for their own work, among them Metropolitan-Vickers Electrical Co., Ltd., which has an apparatus for detecting conducting particles in textile sleeving, a magnetic crack detector and a dilatometer for determination of coefficient of expansion. In addition, the Department of Scientific and Industrial Research arranged a special section illustrative of apparatus and methods used in the laboratories co-operating in this congress.

As regards the papers presented at the Congress, most of them were available in advance; the accounts which follow were prepared from such advance proofs.

\section{Group A (METALs)}

The 77 papers in the Metals Group were subgrouped under four headings: (1) Behaviour as dependent upon temperature; (2) progress of metallography; (3) light metals and their alloys; and (4) workability and wear.

In Sub-Group 1, the mechanism of the creep of metals and creep testing methods receive considerable discussion. H. J. Tapsell (National Physical Laboratory) directs attention to the phenomenon of creep recovery, a continuous contraction after unloading, which may continue in certain cases for thousands of hours after the release of stress. Two possible hypotheses are put forward, and it is considered that the study of creep recovery should assist in furthering the knowledge of the nature of creep. Dr. C. L. Clark and Dr. A. E. White (University of Michigan) summarize two theories concerning the mechanism of creep, on the basis of which the known influences of a number of factors on creep resistance can be readily explained. Dr. A. Nadai briefly surveys the results of work at the Westinghouse Laboratories, and emphasizes, among other things, that methods are needed in industry to shorten the time of creep tests from a duration of three months or more to times of the order of hours or days ; these must be based on a better knowledge of the speed law connecting stress with strain rate.

Dr. U. R. Evans discusses corrosion as influenced by increased temperature, pointing out that at high temperatures the rate of combination between metallic atoms and oxygen atoms is very rapid, and the rate of wastage of metals exposed to hot oxidizing gases is usually only limited by the rate of penetration of oxygen inwards through the oxide-coat, or by the rate of diffusion of metal outwards to the oxygen. The testing of high endurance oxidation-resistant alloys is described by F. E. Bash, of the DriverHarris Co., New Jersey. Improvements in these materials have greatly increased the difficulty and 
the time required in their testing; the present test temperature, $1,175^{\circ} \mathrm{C}$., is $110^{\circ} \mathrm{C}$. higher than that originally standardized, but wires last as long to-day at this temperature as was the case formerly with the lower temperature.

In the sub-group on the progress of metallography, the papers were again classified into sections on micrography, X-ray interference, electron diffraction and emissivity, equilibrium diagrams, non-metallic inclusions, solidification of ingots and recrystalliza. tion.

W. H. Dearden (University of Bristol), contributes a valuable survey of recent progress in the preparation of specimens for macro- and microexamination, with a very full bibliography on etching reagents, and Dr. A. J. Bradley gives an account of the development of quantitative metallographic X-ray methods. Dr. H. J. Gough summarizes the results of his extensive study of the mechanism of deformation and fracture in metals, while Prof. G. I. Finch, in a paper on electron diffraction in the study of metal films and surfaces, emphasizes that the realization of the full advantages of electron diffraction and of the older methods must lie in their future co-operation. Dr. W. Burgers describes the method of electron-optical observation of metal surfaces. This method permits of the study of phases which are stable only at high temperatures, and of the direct observation of transition and recrystallization processes.

In a paper on "The Solidification of Ingots", Dr. C. H. Desch ably summarizes the somewhat conflicting views of various workers on the causes of inverse segregation.

The Sub-Group concerned with light metals and their alloys contains several papers of a more practical nature. Dr. A. G. C. Gwyer and Mr. H. G. Dyson report recent progress in aluminium casting alloys, and emphasize the increasing use of heat-treated alloys and of grain-refining additions such as titanium. Progress in this sphere in America is summarized by E. H. Dix and Zay Jeffries, while Dr. G. Siebel reviews improvements in magnesium alloys leading to increased resistance to corrosion. Dr. J. L. Haughton describes recent work at the National Physical Laboratory on the development of new magnesium alloys, particularly those containing aluminium and silver, and cerium, cobalt and manganese, which have improved physical properties.

\section{Group B (Inorganic Materials)}

Inorganic Materials (Group B) constitute a most interesting section, not only on account of the intrinsic importance of the cements, stones and ceramic materials which it includes, but also because the methods of testing are in a state of active develop. ment. Although these materials are in quite a different class, the methods of testing have been, in the past, greatly influenced by those devised and used for the ductile materials. The proceedings of the Conference may therefore be generally looked to for information as to the tests and procedure which are being found most practicable and reliable.

One of the difficulties met with in carrying out tests is the time required for the materials to mature or 'age', and a typical paper is that in which $\mathbf{A}$. Brund (Härmösand, Sweden) submits the results of tests hastened by means of electric heating. Heat is generated in the paste by alternating current, and thereby accelerates the reaction between water and cement. The resistance is found to decrease during the first period of hardening, reaching its minimum as binding begins and increasing during the later period of hardening. It is claimed that the heat development and curing automatically regulate one another, thus ensuring uniformity of hardness throughout the specimen and a smaller amount of variation in the test results. Variations arising from the personal element introduced in mixing, mould filling and compacting are also a source of difficulty in standardizing tests, and the improvement in this respect effected by the use of a high-frequency vibrator, and the several steps and reasons which led to the use of this machine, are described by Dr. W. H. Glanville (Road Research Laboratory, Harmondsworth). In several papers, suggestions are put forward recommending variations which have been made in laboratory technique and found satisfactory.

Several reports of studies on the control and measurement of the heat of hydration of cements in large masses are presented. Dr. F. M. Lea (Building Research Station, Garston) discusses the merits of the present methods of measuring its value. The 'heat of solution' method is the calculation of the difference of the values for hydrated and unhydrated cement in a nitric-hydrofluoric acid solvent. The adiabatic calorimetric method, in which the samples are stored so that no heat is lost and the temperature therefore rises in proportion to the heat evolved by the hydrating cement, is considered to be more reliable. In "Methods of Testing Cements for Large Dams", B. Hellström, judging from comparative tests carried out at different laboratories in England, Sweden and Norway, regards this latter test as sufficiently accurate for adoption as a routine method. Dealing, on the other hand, with the control of this heat, P. H. Bates (U.S. National Bureau of Standards) directs attention to three different methods by which cements of low heats of hydration can be produced, the first and most usual being to effect a change in composition in one of several possible ways, the second being a process of pre heating the clinker, and the third depending upon a system of partial pre-hydration in an atmosphere of steam at $212^{\circ} \mathrm{F}$. No very definite data are, however, available as to the relative merits of these methods.

Numerous issues are raised in connexion with the action of different qualities of water on cement which is immersed, and several of the contributors deal with one or other of these. In describing some properties of ciment fondu and, in particular, its resistance to the action of soft waters, E. Rengade advances the view that the chemical resistance of a mortar is not necessarily directly related to the solubility of its individual constituents, but depends upon the manner in which these are arranged in the heterogeneous mass of which it is composed. Prof. G. Batta (University of Liège) submits some notes on several causes of disintegration, including solubility of constituents and attack by sea-water and by sulphated waters, this last case also being dealt with by G. Baire (Boulogne-sur-Mer Cement Laboratories) in a paper in which he gives the results of mechanical tests on specimens treated with solutions of the sulphates of magnesia and lime.

On the mechanical side, there are several papers devoted to testing, to the value of vibration as a means of compacting and improving the strength of the mixtures and to the grading and workability of aggregates. In his paper, Dr. Glanville sets out a 
concept of the term 'workability' as a physical property of concrete, and explains its measurement by analysis of the applied work, the useful work and the useful internal work done on a mix, and by the introduction of a compacting factor to define the degree of freedom from air voids at each stage. Considerable interest is attached to a group of papers dealing with the influence of the compressive strength of concrete in relation to the yield point of steel on the degree of safety of beams, particularly those presented by Prof. Rudolf Saliger (Vienna) and by F. G. Thomas (Building Research Station, Garston). In this section, too, a prominent feature is the analysis by Prof. M. Roš (Zurich) of the stresses and deformations produced in cement pipes by internal and external pressures and by bending moments such as may be imposed upon them.

\section{Group C (Organic Materials)}

In Sub-Group 1 (Textiles), an extensive review of chemical tests at present applied to textiles as well as to accessory materials such as oils, sizes and wetting-agents, is given by Dr. H. Phillips, while B.H. Wilsdon provides a similar summary of mechanical tests. Among individual tests, determination of resistance of fabrics to wear is critically examined by R. Severi, who proposes the use of the fabric itself as an abrasive, and by Dr. F. Maillard, who maintains the desirability of abrading the fabric on both sides. Methods for measuring the fastness to light, washing and perspiration of dyed textiles are described by W. D. Appel, whereas a method for determining the fading of dyes and pigments, claimed to give reproducible results independent of the observer, is put forward by R. Toussaint. The detection of damage, especially of a chemical nature, produced during finishing of artificial silk, is discussed in considerable detail by W. Weltzen. Means of assessing the resistance to anærobic bacterial attack of textiles used for building and insulating purposes are described by Dr. J. P. Pfeiffer and H. Eilers. An accurate calorimetric method for determining cotton present in asbestos yarn is proposed by Dr. R. de Benedetti.

Sub-Group 2 (Wood Cellulose) consists of nine papers by authors representing six separate countries.

Cellulose has not yet been isolated as an absolutely pure chemical individual, but it has been established that the celluloses from all known sources have certain well-defined constitutional and structural factors in common. Dr. De Witt Smith (U.S.A.) points out that a wide gap exists between our know. ledge of the cellulose molecular chain and the fibril, which latter is large enough to consist of several million molecular chains side by side. This gap has been bridged to some extent by the discovery that fibrils can be broken down to smaller units which have been variously named 'dermatosomes', 'granules', 'crystals' and 'fusiform bodies'. These smaller units appear to be held together in the fibril by a cementing material of a pectic nature.

So far as wood cellulose is concerned, W. G. Campbell (Great Britain) indicates that the chief constitutional point at issue is the relationship between that portion which consists of anhydroglucose residues and the remainder. The suggestion is advanced that, although immediately after formation all celluloses may be chemically identical, their respective constitutions may be modified by purely physiological agencies which may vary from species to species in the plant kingdom or even from organ to organ in the same species. A second paper on wood cellulose by Dr. Forster (Great Britain) is to be published in the Congress book. Prof. H. Mark (Austria) discusses the present position regarding the influence of fine structure on the properties of artificial fibres. Although artificial fibres, the properties of which emulate those of the natural fibres, have been prepared, research is still required in order to establish all the conditions necessary for the attainment of consistently reproducible results. Dr. G. Hostomský (Czechoslovakia) describes the Hoeppler viscosimeter and discusses its application to the control of rayon pulp manufacture. Four papers by Prof. G. Jayme (Germany), D. Johansson (Sweden) and L. G. Cottrall (Great Britain) respectively, offer a comprehensive review of current practice in the testing of pulp and paper.

Sub-Group 3 (Timber Preservation) consists of ten papers dealing with the structure, mechanical properties and preservation of timber. A. Nowak (Austria) mentions recent successful moisture proofing of plywood, etc., by impregnation with wax dissolved in an organic solvent, the solvent being afterwards recovered. Owing to the use of creosote for other purposes, many countries are turning to oil emulsions and water-soluble salts for preserving timber against decay. Leise (Germany) further describes the use of water-soluble salts, and mentions the development of the bichromate mixtures which, by depositing insoluble compounds in the wood, are rendered highly resistant to leaching. The lack of a uniform practical definition for the fire resistance of wood is mentioned by E. Azzarello (Italy), who describes four tests which he has adopted for inflammability, flame propagation, flame penetration and rapidity of carbonization. A. Breazzano (Italy) describes a laboratory toxicity test for wood preservatives in which thin samples of wood soaked in the preservative solution are placed in large tubes, and a small piece of active inoculum attached to one face of the sample. The toxicity of the preserva. tive is measured by the minimum concentration which will prevent the hyphæ passing through the thin slip of wood and showing on the opposite face. The author claims that this method gives maximum accuracy and much quicker results than the method adopted at the Berlin Conference in 1930.

The use of large wooden beams built up of pieces of relatively small dimensions is an increasingly im. portant aspect of wood utilization. P. T. Landsem (U.S.A.) describes the properties of such beams and quotes the efficiencies of the various types of connexions. Using the modern type of ring shear connectors, it is possible to obtain an efficiency of 95 per cent, whilst beams built up of laminations placed horizontally and glued together are easily made stronger and stiffer than equivalent solid beams by proper selection of material.

Products discussed in Sub-Group 4 (Ageing of Organic Materials) comprise hydrocarbon oils, bitumens, rubber and some textiles. Methods of following the course of oxidation of mineral oils in general are discussed by Dr. G. Barr, while the detection of ageing in oils and bitumens used for special purposes, chiefly lubrication and insulation, is dealt with by Dr. F. Evers and by Dr. H. Stäger. Rapid methods for testing the physical properties of asphalts and bitumens are described by Prof. R. Matthis, who also proposes the use of $p H$ determinations for testing the ageing of materials soluble in or extractable by water. The causes, effects and methods of detection of ageing in vulcanized rubber are brought under review by B. D. 
Porritt and Dr. J. R. Scott. Methods used in the United States for testing ageing of rubber, paper and silk are described by W. E. Emley. The testing of road tar is discussed by G. Batta and that of asphaltic bitumens by Dr. J. P. Pfeiffer and R. N. J. Saal.

A general tendency towards elimination of the personal factor in testing is discernible in SubGroup 5 (Colours and Varnishes), as may be seen from the general review by Dr. L. A. Jordan of methods of assessing behaviour of paint films in practice, and the description by Dr. E. Rossmann of test methods used in Germany. An apparatus for measuring the fastness of colours to soap solutions, water and perspiration, also designed to eliminate the personal factor, is described by W. Kaczkowski, while Prof. A. R. Matthis puts forward a simple and rapid method of measuring fluidity of oils such as are used in the paint and varnish industry. The corrosive action of insulating varnishes on copper receives attention in a paper by Dr. G. Rossi. Theoretical considerations of the effect of oxidation, polymerization and addition of plasticizers on the molecular structure of oil films are made use of by Dr. A. V. Blom to explain the effect of such agents on the mechanical properties of the paint and varnish films afterwards produced. A plea for more rational terminology in the industry is brought forward by H. Rabaté.

\section{Group D (Subjects of General Importance)}

The papers comprising Group D of the Congress are described as covering "Subjects of General Importance". They actually fall into three subgroups: (1) the relation between the results of laboratory tests and behaviour in use and service; (2) the bearing of recent advances in physics and chemistry on the knowledge of materials; and (3) the properties of materials for the thermal and acoustical insulation of buildings.

The papers under ( 1 ) deal in a general way with problems which are more fully discussed in other sections, in relation to specific materials. The reviews of testing methods do not bring anything new before the Congress, but three papers, which from their titles may raise more important questions, have not been received in time for printing in advance. A paper by Sir Robert Hadfield and S. A. Main directs attention to the impossibility of imitating service conditions exactly in any laboratory tesi, and to the fact that most such tests are really designed to ensure that a given material conforms to a standard which has been found in practice to be satisfactory. It is pointed out that there is still no satisfactory means of determining resistance to abrasion, or the wearing quality of cutlery, whilst the behaviour of such parts as the pistons and piston rods of steam and pneumatic hammers under repeated shock is still imperfectly understood. Accelerated tests for resistance to corrosion are also very uncertain in their indications. M. Roš deals with the general question of factors of safety, giving values for a number of concrete instances.

Sub-Group 2 includes, besides several papers of a general character, an account of the methods to be adopted in testing for flaws in metals by means of gamma rays, by $\mathbf{F}$. Guyot, and a short comparison between the methods of testing by X-rays and by radium, by Dr. V. E. Pullin. A. Pogány describes the study of the propagation of cracks in such masses as cement or concrete while under load in a testing machine by means of a microscope employing vertical polarized light. The gradual separation of the grain of sand from the matrix in a cement briquette can be clearly followed in this way. Sir Gilbert Morgan and his colleagues review the principal types of plastic materials of chemical origin, including syn. thetic resins and rubber-tar products, together with an account of the improvement of tar for road purposes by adding to it a calcium soap. The equations which have been proposed to describe the flow of dispersed systems are surveyed by M. Reiner.

The third sub-group is more homogeneous. The problems of insulating buildings against heat and sound are closely related, although the best materials for the one purpose are not necessarily the most suitable for the other. Several papers deal with the practical methods of studying the efficiency of different means of insulation against sound, par. ticulars being given of the laboratories at Brussels, Berlin, Stockholm and Teddington, whilst P. Sabine, of the Acoustics Laboratory at Geneva, Ill., in describing the methods adopted by the American Standards Association, urges a careful standardization of test procedure among the various laboratories which are co-operating in this field. It is desirable that, by applying a correction factor to the results from any given laboratory, comparable figures should be obtained from which coefficients of wide practical applicability can be derived. Porous materials, such as slag or glass wool or various organic fibres, are used for both thermal and acoustical insulation, as is a construction consisting of sheets of solid material separated by air spaces. Dr. E. Griffiths refers to the use of lightweight concrete, made by mixing with the cement some substance which can cause the evolution of a gas and the production of a stable foam. With such an aggregate as pumice, foamed slag, or expanded slate, a very light concrete of open texture is obtained, with fair mechanical strength. The subject of protection against noise is one of public interest at present, and this series of papers provides much useful information concerning it.

\section{Heredity versus Environment}

$I^{\mathrm{N}}$ a paper recently presented before the Eugenics Society, Dr. David Forsyth returns to that interminable argument 'Heredity versus Environment'. By him, heredity is taken to imply transmission from one generation to another, this transmission comprising structural and functional tendencies to develop organic life. By environment he understands the conditions around an organism. He has been examining the commonly accepted view that heredity and environment play indispensable parts in development, and that each operates separately from the other, and now finds it quite impossible to entertain this view any longer.

If, Dr. Forsyth argues, heredity and environment are indeed independent of each other, then it should be possible logically to trace the extent of the sphere of influence of each, their influences should be detect. able separately, and their origins should be different. If this should prove on examination to be impracticable, then it must become necessary to jetison the present-day concept of heredity and environment as being two discreet forces, and to replace this by another more in harmony with the facts. If, as is done nowadays, heredity, as a term, is applied only 